\section{OPEN ACCESS}

Edited by:

Jing-Yan Han,

Peking University, China

Reviewed by:

Gerd Heusch,

University of Duisburg-Essen,

Germany

Claudia Penna

University of Turin, Italy

*Correspondence:

Kefang Guo

Dr_guokefang@163.com

${ }^{\dagger}$ Co-first authors

Specialty section: This article was submitted to

Vascular Physiology,

a section of the journa

Frontiers in Physiology

Received: 18 January 2019 Accepted: 08 April 2019

Published: 29 April 2019

Citation:

Wang H, Lyu Y, Liao Q, Jin L, Xu L, Hu Y, Yu Y and Guo K (2019)

Effects of Remote Ischemic

Preconditioning in Patients Undergoing Off-Pump Coronary

Artery Bypass Graft Surgery.

Front. Physiol. 10:495.

doi: 10.3389/fphys.2019.00495

\title{
Effects of Remote Ischemic Preconditioning in Patients Undergoing Off-Pump Coronary Artery Bypass Graft Surgery
}

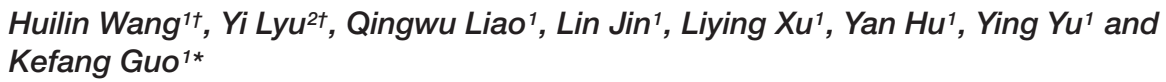

${ }^{1}$ Department of Anesthesiology, Zhongshan Hospital, Fudan University, Shanghai, China, ${ }^{2}$ Department of Anesthesiology, Yunnan Baoshan Anli Hospital, Baoshan, China

Purpose: This study aimed to evaluate effects of remote ischemic preconditioning (RIPC) on myocardial injury in patients undergoing off-pump coronary artery bypass graft surgery (OPCABG).

Methods: Sixty-five patients scheduled for the OPCABG were randomly assigned to control $(n=32)$ or RIPC group $(n=33)$. All patients received general anesthesia. Before the surgical incision, RIPC was induced on an upper limb with repeated 5-min ischemia and 5-min reperfusion for four times. Blood samples were collected from right internal jugular vein. Plasma levels of IL-6, IL-8, IL-10, TNF- $\alpha$, cTnT, HFABP, IMA, and MDA were detected at pre-operatively and 0, 6, 18, 24, 48, 72, and $120 \mathrm{~h}$ after the surgery. Left internal mammary artery (LIMA) and great saphenous vein (GSV) was cut into 2-3 mm for Western blot analysis of Hif- $1 \alpha$.

Results: In the present study, RIPC treatment significantly reduced plasma levels of cardiac troponin $T(p<0.05)$, heart-type fatty acid binding protein $(p<0.05)$, ischemia modified albumin $(p<0.05)$, malondialdehyde $(p<0.05)$, as well as plasma levels of proinflammatory cytokines including IL-6, IL-8, and TNF- $\alpha(P<0.05$, respectively). RIPC treatment significantly increased hypoxia-inducible factor- $1 \alpha(p<0.05)$ expression as well. Mechanical ventilation time for postoperative patients was shortened in RIPC group than those in control group ( $17.4 \pm 3.8 \mathrm{~h}$ vs. $19.7 \pm 2.9 \mathrm{~h}$, respectively, $p<0.05)$.

Conclusion: RIPC by upper limb ischemia shortens mechanical ventilation time in patients undergoing OPCABG. RIPC treatment reduces postoperative myocardial enzyme expression and pro-inflammatory cytokine production. RIPC is a protective therapeutic approach in the coronary artery bypass graft surgery.

Keywords: off-pump coronary artery bypass graft surgery, remote ischemic preconditioning, myocardial protection, outcome, protective therapeutic approach

Abbreviations: $c \operatorname{TnT}$, cardiac troponin T; GSV, great saphenous vein; HFABP, heart-type fatty acid binding protein; Hif, hypoxia-inducible factor; IMA, ischemia modified albumin; LIMA, left internal mammary artery; MDA, malondialdehyde; OPCABG, off-pump coronary artery bypass graft surgery; RIPC, remote ischemic preconditioning; ROS, reactive oxygen species. 


\section{INTRODUCTION}

With the change of lifestyle and eating habits, the incidence of coronary artery disease (CAD) in China increased gradually (reported by Xue and $\mathrm{Xu}, 2017$ ). Those who with multiple CAD need surgery. Off-pump coronary artery bypass graft (OPCABG) is the preferred surgical procedure. Even so, myocardial ischemia-reperfusion injury often occurs after OPCABG and this can not be avoided completely (Chowdhury et al., 2008). Thus, great efforts should be made to alleviate myocardial injury. Remote ischemic preconditioning (RIPC), a non-invasive and operable intervention in the clinic, has drawn the attention of clinicians in recent years.

The phenomenon of RIPC was first reported by Przyklenk et al. (1993) in the end of last century. After several years, the paradigm of "cardioprotection at a distance" by ischemic conditioning was quickly extended to other tissues and organs and to longer distances from the heart (Heusch, 2018). The underlying mechanisms probably include a release of transferable humoral from the perfused tissue and neuronal reflexes (Heusch et al., 2015).

It has been reported that RIPC could be a potential protective approach for perioperative complication (Cheung et al., 2006; Hausenloy et al., 2007). In patients undergone surgical coronary revascularization under isoflurane anesthesia, RIPC was confirmed to improve clinical outcome (Thielmann et al., 2013; Kleinbongard et al., 2018). However, the benefits from RIPC during cardiovascular surgery were not confirmed in other two large phase III trials (Hausenloy et al., 2015; Meybohm et al., 2015). Meanwhile, the effects of RIPC on myocardial injury as well as clinical outcome in patients undergoing OPCABG are inconclusive. In the present study, we conducted a randomized clinical trial on patients undergoing OPCABG. To augment the protective effect of RIPC, RIPC was given as upper limb ischemia. Myocardial injury was assessed by measuring plasma cTnT, IMA, HFABP level at baseline and after operation. Inflammatory reaction (IL-6, IL-8, TNF$\alpha$, and IL-10), Hif- $1 \alpha$ and oxidation index (MDA) were also examined. Clinical parameters analysis was used to assess shortterm prognosis.

\section{MATERIALS AND METHODS}

\section{Patients}

The present study was approved by Ethnics Committee, Zhongshan Hospital, Fudan University ${ }^{1}$. All patients recruited in the present study were signed up with written consent before enrollment. Exclusion criteria of the present study include age $>80$ years, major combined surgery (such as valve surgery), myocardial infarction in the last 28 days, severe infection in the last 7 days, severe hepatic, renal, pulmonary or hematological disease; use of an inotropic agent or a mechanical assist device; left ventricular ejection fraction less than $40 \%$; or peripheral

${ }^{1}$ https://clinicaltrials.gov/\#NCT03340181 vascular disease affecting upper limbs. Patients were randomly assigned to control or RIPC group using a computer-generated random list after they entering the operating room. Both surgeons and anesthesiologists were blinded to the assignments.

\section{Anesthesia Method}

Patients were given $40 \%$ concentration of oxygen inhalation by mask, right internal jugular vein catheterization and left radial artery catheterization were completed by anesthetist under ECG and pulse oxygen saturation monitoring. Anesthesia was induced with i.v. midazolam $(0.05 \mathrm{mg} / \mathrm{kg})$, etomidate $(0.3-0.4 \mathrm{mg} / \mathrm{kg})$, sufentanil $(0.4-0.5 \mu \mathrm{g} / \mathrm{kg})$, and rocuronium $(0.9-1.2 \mathrm{mg} / \mathrm{kg})$. The trachea was intubated with a tracheal tube ( $7 \#$ for women and 7.5\# for men) under the exposure of visual laryngoscope and lungs were mechanically ventilated with $50 \%$ concentration of oxygen to maintain an end-tidal carbon dioxide tension of 35$40 \mathrm{mmHg}$. Anesthesia was maintained by sevoflurane $(0.8-1.3$ $\mathrm{MAC})$ to achieve a bispectral index of 40-60. Rocuronium (0.2$0.3 \mathrm{mg} / \mathrm{kg})$ and sufentanil $(0.3-0.4 \mu \mathrm{g} / \mathrm{kg})$ were added according to the clinical situation.

\section{RIPC Procedure}

Remote ischemic preconditioning was induced with repeated 5-min ischemia and 5-min reperfusion on the upper limb for four times. By using a blood pressure cuff inflation, patients in RIPC group were exposed to a pressure $40 \mathrm{mmHg}$ higher than the systolic arterial pressure, whereas control group had sham placement of the pressure cuff without inflation. RIPC procedure was performed right after the end of anesthesia induction.

\section{Surgical Method}

Incision began after the whole RIPC procedure had been done. Anastomoses were constructed using an intracoronary shunt (Medtronic, Minneapolis, MN, United States). The left internal mammary artery (LIMA) and the great saphenous vein (GSV) were harvested primarily. Depending on the patients' target vessel characteristics, other grafts such as the right internal mammary artery and the left radial artery were used in addition. Papaverine solution was used to avoid grafts vasospasm. Heparin was used $(1 \mathrm{mg} / \mathrm{kg}$ per patient primarily) to achieve ACT value over $280 \mathrm{~s}$.

\section{Blood Sample Collection and Analysis}

Blood samples were collected from right internal jugular vein preoperatively (Preop), and after the surgery (Postop 0, 6, 18, 24, 48,72 , and $120 \mathrm{~h}$ ). After centrifuged at $1000 \times g$ for $10 \mathrm{~min}$, plasma samples were frozen at $-80^{\circ} \mathrm{C}$ for later analysis. Plasma levels of inflammatory cytokines IL-6, IL-8, IL-10, and TNF$\alpha$ were measured with a Luminex protein suspension array system (Bio-plex 200; Bio-Rad) according to manufacturer's instructions. Plasma levels of cTnT (Human cTnT ELISA Kit, MBS2508285, MyBioSource, San Diego, CA, United States), HFABP (Human FABP3 DuoSet ELISA, DY1678, R\&D) IMA (Human IMA ELISA Kit, MBS2515981, MyBioSource, San Diego, CA, United States), and MDA (Human MDA assay kit, A0032, Jiancheng Inc., Jiangsu, China) were measured according to manufacturer's instruction. 


\section{Tissue Protein Extraction and Determination by Western Blot Analysis}

After dissociation, LIMA and GSV was cut into 2-3 $\mathrm{mm}$ for Western blot analysis of Hif- $1 \alpha$ ( $n=13$ in each group). The tissue samples were homogenized in Radio Immunoprecipitation Assay (RIPA, Cell Signaling, Boston, MA, United States). After centrifuged with $12000 \mathrm{rpm}$ at $4^{\circ} \mathrm{C}$ for $10 \mathrm{~min}$, supernatant was collected. Protein concentration were measured with bicinchoninic acid method (Bio-Rad, Hercules, CA, United States). The membranes were incubated with primary antibodies Hif-1 $\alpha$ (1:1000; H1alpha67; Abcam, Cambridge, MA, United States) and GAPDH (1:2000; A2228; Sigma-Aldrich, St. Louis, MO, United States) at $4^{\circ} \mathrm{C}$ for overnight and corresponding secondary antibody at room temperature for $2 \mathrm{~h}$. The detected bands were visualized with an ECL detection kit (Pierce, IL, United States).

\section{Statistical Analysis}

As showed in reference, prolonged ICU stay is a powerful predictor of adverse outcome after cardiac surgery (Mahesh et al., 2012). With a two-sided significance level $\alpha$ of 0.05 and study power at $80 \%$, it was estimated that 32 patients would be required per group in order to reach the conditions that RIPC could reduce the ICU stay time by $3 \mathrm{~h}$ (Sakpal, 2010). All datas are presented as the means $\pm \mathrm{SD}$. The comparison of enumerated data between the treatment groups was conducted using the chisquare test, while an unpaired $t$-test was applied to compare measurement data where appropriate. Plasma concentrations of cTnT, HFABP, IMA, MDA, and inflammatory cytokines were analyzed by 2-way (group, time) ANOVA for repeated measures followed by Fisher's post hoc tests. SPSS version 19.0 for Windows (IBM Corporation, Armonk, NY, United States) were used for the statistical analyses. A value of $P<0.05$ was considered as statistically significantly different.

\section{RESULTS}

The characteristics of patients in the two groups were comparable regarding their gender, age and body weight (Table 1). There were no significant differences in operation time (including bridging vessels dissociation time, bridging vessels anastomosis time and duration of surgery) between two groups. Patients in the control group had a longer mechanical ventilation time than those in RIPC group (control vs. RIPC: $19.7 \pm 2.9 \mathrm{~h}$ vs. $17.4 \pm 3.8 \mathrm{~h}$, $p<0.05$ ), while had similar amount of time staying the Intensive Care Unit $(p>0.05)$ and in regular wards $(p>0.05)$ (Table 2).

\begin{tabular}{|c|c|c|c|}
\hline Variable & Control group $(n=32)$ & RIPC group $(n=33)$ & $P$ \\
\hline Age (years) & $59.8 \pm 9.2$ & $61.3 \pm 8.7$ & 0.587 \\
\hline Male & $23(72)$ & $25(75)$ & 0.251 \\
\hline Weight (kg) & $64.5 \pm 10.3$ & $66.7 \pm 9.8$ & 0.733 \\
\hline
\end{tabular}

Incidences of post-operative complications including hospital death were comparable in the two groups as well. However, no significant differences were observed between the two groups during the period of observation (Table 3).

\section{Myocardial Injury}

Before the surgery, plasma levels of IMA in two groups were comparable. After the surgery, the IMA levels in control group were increased. RIPC treatment significantly reduced the IMA

TABLE 2 | Operative characteristics and short-term outcome.

\begin{tabular}{lccc}
\hline Variable & Control group $(\boldsymbol{n}=\mathbf{3 2})$ & RIPC group $(\boldsymbol{n}=\mathbf{3 3})$ & $\boldsymbol{P}$ \\
\hline $\begin{array}{l}\text { Bridging vessels } \\
\text { dissociation time } \\
\text { (min) }\end{array}$ & $64.1 \pm 18.8$ & $68.4 \pm 24.2$ & 0.403 \\
$\begin{array}{l}\text { Bridging vessels } \\
\text { anastomosis time }\end{array}$ & $100.3 \pm 26.4$ & $100.1 \pm 44.6$ & 0.987 \\
$\begin{array}{l}\text { (min) } \\
\begin{array}{l}\text { Duration of surgery } \\
\text { (min) }\end{array}\end{array}$ & $233.1 \pm 36.8$ & $235.1 \pm 43.4$ & 0.841 \\
$\begin{array}{l}\text { Mechanical } \\
\text { ventilation time (h) }\end{array}$ & $19.7 \pm 2.9$ & $17.4 \pm 3.8$ & $0.006^{*}$ \\
ICU stay (d) & $1.8 \pm 1.1$ & & \\
Hospital stay (d) & $7.9 \pm 2.3$ & $7.7 \pm 1.0$ & 0.673 \\
\hline
\end{tabular}

Data given as mean $\pm S D$. ICU, intensive care unit. Patients in the control group had a longer mechanical ventilation time than those in RIPC group. There were no significant differences in other operative characteristics, ICU stay or hospital stay between the two groups.

TABLE 3 | Incidences of post-operative complications.

\begin{tabular}{|c|c|c|c|}
\hline $\begin{array}{l}\text { Major } \\
\text { postoperative } \\
\text { complications }\end{array}$ & $\begin{array}{l}\text { Control group } \\
\quad(n=32)\end{array}$ & $\begin{array}{l}\text { RIPC group } \\
\quad(n=33)\end{array}$ & $P$ \\
\hline AKI, n (\%) & $4(12.5)$ & $4(12.1)$ & 0.948 \\
\hline $\begin{array}{l}\text { Renal failure } \\
\text { requires } \\
\text { dialysis, n (\%) }\end{array}$ & $0(0)$ & $0(0)$ & $\mathrm{N} / \mathrm{A}$ \\
\hline $\begin{array}{l}\text { Abnormal heart } \\
\text { rhythm, } n(\%)\end{array}$ & $5(15.6)$ & $2(6.1)$ & 0.339 \\
\hline Delirium, n (\%) & $1(3.1)$ & $0(0)$ & 0.492 \\
\hline $\begin{array}{l}\text { Pneumonia, n } \\
\text { (\%) }\end{array}$ & $5(15.6)$ & $3(9.1)$ & 0.672 \\
\hline $\begin{array}{l}\text { Postoperative } \\
\text { infection, n (\%) }\end{array}$ & $1(3.1)$ & $1(3)$ & 0.965 \\
\hline $\begin{array}{l}\text { Mechanical } \\
\text { ventilation } \\
>48 \mathrm{~h}, \mathrm{n}(\%)\end{array}$ & $0(0)$ & $0(0)$ & N/A \\
\hline $\begin{array}{l}\text { Reoperation, n } \\
\text { (\%) }\end{array}$ & $0(0)$ & $0(0)$ & N/A \\
\hline Stroke, n (\%) & $0(0)$ & $0(0)$ & N/A \\
\hline $\begin{array}{l}\text { Hospital death, } \\
\text { n (\%) }\end{array}$ & $0(0)$ & $0(0)$ & $\mathrm{N} / \mathrm{A}$ \\
\hline $\begin{array}{l}\text { 30-day } \\
\text { mortality, n (\%) }\end{array}$ & $0(0)$ & $0(0)$ & N/A \\
\hline
\end{tabular}

Data given as median (lower-upper quartiles), $n$ (\%). AKI, acute kidney injury. There were no significant differences between the two groups during the period of observation. 
levels after $18 \mathrm{~h}$ (control vs. RIPC: $15.48 \pm 6.60 \mathrm{ng} / \mathrm{ml}$ vs. $9.82 \pm 3.61 \mathrm{ng} / \mathrm{ml}, p<0.05$ ) (Table 4).

Before the surgery, plasma levels of HFABP in two groups were comparable. After the surgery, HFABP levels in control group were transiently increased. RIPC treatment significantly reduced the HFABP levels at $0 \mathrm{~h}$ (control vs. RIPC: $5.56 \pm 2.99 \mathrm{ng} / \mathrm{ml}$ vs. $3.72 \pm 2.03 \mathrm{ng} / \mathrm{ml}, p<0.05$ ) and $6 \mathrm{~h}$ (control vs. RIPC: $4.21 \pm 2.40 \mathrm{ng} / \mathrm{ml}$ vs. $2.58 \pm 2.02 \mathrm{ng} / \mathrm{ml}, p<0.05)$ (Table 4).

Before the surgery, plasma levels of cTnT in two groups were comparable. After the surgery, the cTnT level in both group were increased. RIPC treatment significantly reduced the cTnT

TABLE 4 | Myocardial injury factors (IMA and HFABP).

\begin{tabular}{lllllll}
\hline & \multicolumn{2}{c}{ IMA $(\mathbf{n g} / \mathbf{m l})$} & & \multicolumn{2}{c}{ HFABP $(\mathbf{n g} / \mathbf{m l})$} \\
\cline { 2 - 3 } \cline { 5 - 6 } & Con $(\boldsymbol{n}=\mathbf{3 2})$ & RIPC $(\boldsymbol{n}=\mathbf{3 3})$ & & Con $(\boldsymbol{n}=\mathbf{3 2})$ & RIPC ( $\boldsymbol{n}=\mathbf{3 3})$ \\
\hline Preop & $10.56 \pm 3.03$ & $11.17 \pm 4.42$ & & $2.81 \pm 2.26$ & $2.66 \pm 1.76$ \\
Postop 0 h & $13.14 \pm 4.75$ & $11.63 \pm 4.20$ & & $5.56 \pm 2.99^{*}$ & $3.72 \pm 2.03^{*} \Delta$ \\
Postop 6 h & $15.65 \pm 5.03^{*}$ & $10.55 \pm 4.44$ & & $4.21 \pm 2.40^{* \#}$ & $2.58 \pm 2.02^{\#} \Delta$ \\
Postop 18 h & $15.48 \pm 6.60^{*}$ & $9.82 \pm 3.61 \Delta$ & & $2.96 \pm 2.22^{\#} \boldsymbol{\Delta}$ & $2.07 \pm 1.62^{\#}$ \\
\hline
\end{tabular}

Data given as mean $\pm S D$. HFABP, heart-type fatty acid binding protein. $I M A$, ischemia modified albumin. Preop, pre-operation. Postop, post-operation. $\Delta P<0.05$ vs. control group; ${ }^{*} P$ and $\mathbf{\Delta} P<0.05$ vs. within group. Compared with Preop, ${ }^{*} P<0.05$, Compared with Postop $0 h$, ${ }^{\#} P<0.05$, Compared with Postop $6 h, \mathbf{\Delta} P<0.05$.

TABLE 5 | Myocardial injury factors (cTnT).

\begin{tabular}{lcc}
\hline & \multicolumn{2}{c}{ cTnT $(\mathbf{n g} / \mathbf{m l})$} \\
\cline { 2 - 3 } & Con $(\boldsymbol{n}=\mathbf{3 2})$ & RIPC $(\boldsymbol{n}=\mathbf{3 3})$ \\
\hline Preop & $0.023 \pm 0.029$ & $0.018 \pm 0.017$ \\
Postop 6 h & $0.314 \pm 0327^{*}$ & $0.200 \pm 0.113^{*}$ \\
Postop 24 h & $0.462 \pm 0.765^{*}$ & $0.213 \pm 0.108^{*}$ \\
Postop 48 h & $0.532 \pm 0.989$ & $0.187 \pm 0.131^{*}$ \\
Postop 72 h & $0.384 \pm 0.695$ & $0.144 \pm 0.136^{*}$ \\
Postop 120 h & $0.273 \pm 0.397^{*}$ & $0.108 \pm 0.110^{* \#} \boldsymbol{\Delta} \Delta$
\end{tabular}

Data given as mean $\pm S D$. cTnT, cardiac troponin $T . \Delta P<0.05$ vs. control group; ${ }^{*} P$ and $\mathbf{\Delta} P<0.05$ vs. within group. Compared with Preop, $* P<0.05$, Compared with Postop $0 \mathrm{~h},{ }^{\#} P<0.05$, Compared with Postop $6 \mathrm{~h}, \mathbf{\Delta} P<0.05$. levels after $120 \mathrm{~h}$ (control vs. RIPC: $0.273 \pm 0.397 \mathrm{ng} / \mathrm{ml}$ vs. $0.108 \pm 0.110 \mathrm{ng} / \mathrm{ml}, p<0.05$ ) (Table 5).

\section{Systemic Inflammatory Response}

Before the surgery, both groups had comparable plasma levels of IL-6, IL-8, and TNF- $\alpha$. After the surgery, plasma levels of IL6 , IL-8, and TNF- $\alpha$ were significantly increased in both groups. RIPC treatment significantly reduced the plasma levels of IL6, IL- 8 after $0 \mathrm{~h}$ (control vs. RIPC: $0.88 \pm 0.39 \mathrm{ng} / \mathrm{ml}$ vs. $0.49 \pm 0.34 \mathrm{ng} / \mathrm{ml}, p<0.05$ ) (control vs. RIPC: $1.41 \pm 0.91 \mathrm{ng} / \mathrm{ml}$ vs. $0.78 \pm 0.37 \mathrm{ng} / \mathrm{ml}, p<0.05$ ), $6 \mathrm{~h}$ (control vs. RIPC: $10.81 \pm 6.61 \mathrm{ng} / \mathrm{ml}$ vs. $4.74 \pm 2.62 \mathrm{ng} / \mathrm{ml}, p<0.05)$ (control vs. RIPC: $3.99 \pm 2.36 \mathrm{ng} / \mathrm{ml}$ vs. $2.24 \pm 1.46 \mathrm{ng} / \mathrm{ml}$, $p<0.05$ ), and $18 \mathrm{~h}$ (control vs. RIPC: $7.78 \pm 4.80 \mathrm{ng} / \mathrm{ml}$ vs. $2.89 \pm 1.40 \mathrm{ng} / \mathrm{ml}, p<0.05$ ) (control vs. RIPC: $3.61 \pm 2.00 \mathrm{ng} / \mathrm{ml}$ vs. $1.93 \pm 0.91 \mathrm{ng} / \mathrm{ml}, p<0.05)$, and TNF- $\alpha$ after $6 \mathrm{~h}$ (control vs. RIPC: $2.32 \pm 0.79 \mathrm{ng} / \mathrm{ml}$ vs. $1.55 \pm 0.87 \mathrm{ng} / \mathrm{ml}$, $p<0.05$ ) and $18 \mathrm{~h}$ (control vs. RIPC: $2.60 \pm 1.04 \mathrm{ng} / \mathrm{ml}$ vs. $1.72 \pm 0.91 \mathrm{ng} / \mathrm{ml}, p<0.05)$.

Before the surgery, both groups had comparable levels of IL-10 in plasma. Plasma level of IL-10 were transiently, but significantly increased after the surgery $(0 \mathrm{~h})$ and then decreased. The plasma levels of IL-10 decreased largely in control group after $6 \mathrm{~h}$ (control vs. RIPC: $0.59 \pm 0.34 \mathrm{ng} / \mathrm{ml}$ vs. $1.36 \pm 0.80 \mathrm{ng} / \mathrm{ml}$, $p<0.05$ ) and $18 \mathrm{~h}$ compared with RIPC group (control vs. RIPC: $0.53 \pm 0.32 \mathrm{ng} / \mathrm{ml}$ vs. $0.77 \pm 0.45 \mathrm{ng} / \mathrm{ml}, p<0.05$ ) (Table 6).

\section{Oxidative Index}

Before the surgery, both groups had comparable levels of MDA in plasma. Plasma level of MDA were significantly increased after the surgery. RIPC treatment significantly reduced the plasma levels of MDA at $0 \mathrm{~h}$ (control vs. RIPC: $66.07 \pm 3.46 \mathrm{nmol} / \mathrm{ml}$ vs. $50.26 \pm 3.22 \mathrm{nmol} / \mathrm{ml}, p<0.05$ ) (Table 7).

\section{Hif- $1 \alpha$ Protein Expression in LIMA and GSV}

In the present study, RIPC group had a higher level of Hif- $1 \alpha$ protein in LIMA samples when compared with control group (control vs. RIPC: $0.43 \pm 0.04$ vs. $0.63 \pm 0.03, p<0.05$ ). However, the Hif-1 $\alpha$ levels in vein were comparable in RIPC and

TABLE 6 | Systemic inflammatory response.

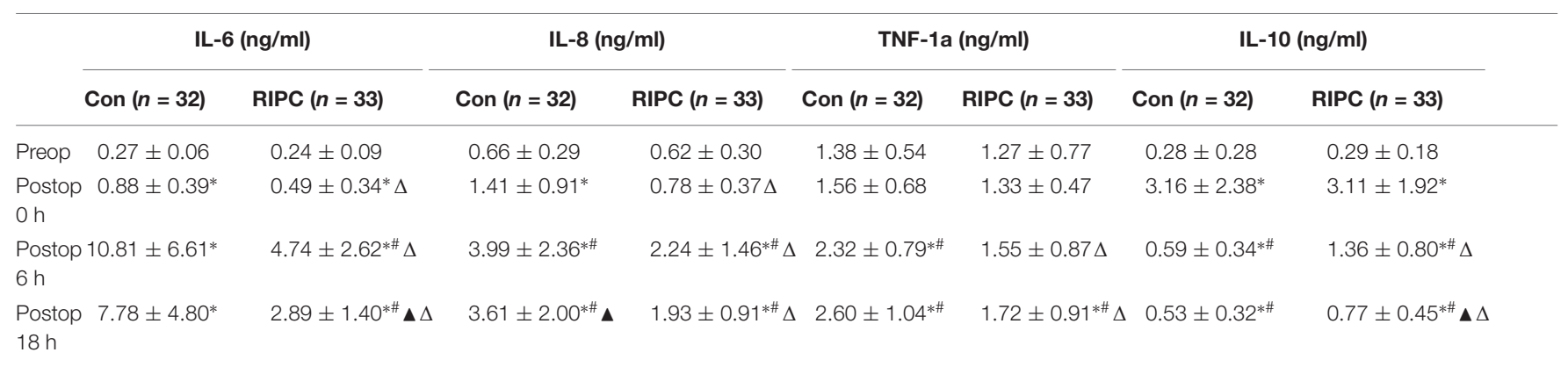

Data given as mean $\pm S D$. IL, interleukin. TNF, tumor necrosis factor. $\Delta P<0.05$ vs. control group; $* \# P$ and $\mathbf{\Delta} P<0.05$ vs. within group. Compared with Preop, $* P<0.05$, Compared with Postop $0 \mathrm{~h},{ }^{\#} P<0.05$, Compared with Postop $6 h, \mathbf{\Delta} P<0.05$. 
control group (control vs. RIPC: $0.45 \pm 0.03$ vs. $0.53 \pm 0.03$, $p>0.05)$ (Figure 1).

\section{DISCUSSION}

In the present study treatment with remote ischemia preconditioning significantly shortens mechanical ventilation time and reduces myocardial damage by decreasing oxidative stress and reducing productions of inflammatory cytokines.

Compared with traditional coronary artery bypass grafting by pump, off-pump coronary artery bypass grafting has some advantageous effects, including shortening post-operation mechanical ventilation time, a decrease in cardiac complication, and improvement of patient's recovery. However, myocardial injury is an unavoidable event of the surgery (Sellke et al., 2010).

TABLE 7 | Oxidative index.

\begin{tabular}{lcc}
\hline & \multicolumn{2}{c}{ MDA (nmol/ml) } \\
\cline { 2 - 3 } & Con $(\boldsymbol{n}=\mathbf{3 2})$ & RIPC $(\boldsymbol{n}=\mathbf{3 3})$ \\
\hline Preop & $48.14 \pm 4.14$ & $47.25 \pm 3.32$ \\
Postop 0 h & $66.07 \pm 3.46$ & $50.26 \pm 3.22^{*}$ \\
Postop 6 h & $79.30 \pm 5.13$ & $71.66 \pm 4.87$ \\
Postop 18 h & $54.51 \pm 4.10$ & $45.97 \pm 3.10$ \\
\hline
\end{tabular}

Data given as mean $\pm S D$. MDA, malonaldehyde. ${ }^{*} P<0.05$ vs. control group.
Regional ischemic "preconditioning" was first reported to reduce infarct size after transient occlusion of coronary artery (Ahmad et al., 2014). Later, remote preconditioning in limb is reported to attenuate myocardial injury in children undergoing congenital heart defect repair (Wu et al., 2018). However, the effectiveness of RIPC cardioprotection in adult patients undergoing cardiac surgery remains controversial. It is reported that RIPC reduces the release of myocardial enzymes after the cardiac surgery, but without clinical benefit (Ahmad et al., 2014; Benstoem et al., 2017; Xie et al., 2018). Thielmann et al. (2013) reported that RIPC provided perioperative myocardial protection and improved the prognosis of patients undergoing elective CABG surgery in a single-center randomized, double-blind, controlled trial. While another two large-scale, prospective, randomized, shamcontrolled multi-center phase III trials (ERICCA and RIPHeart) show neutral results for both composite primary endpoints and troponin release by RIPC in patients underwent cardiac surgery under ischaemic cardiac arrest and cardiopulmonary bypass (Hausenloy et al., 2015; Meybohm et al., 2015). These inconsistent findings are probably related to differences in study protocols, confounding comorbidities, anesthetic regimens, and in surgical procedures, techniques, and protection regimens. The most plausible explanation for the lack of protection in ERICCA and RIPHeart is the use of propofol (more than $90 \%$ of patients in ERICCA and all patients in RIPHeart), a lipidsoluble anesthetic agent, eliminating reactive oxygen species (ROS) and interfering with the signal transduction pathway of RIPC somewhere upstream of STAT5 (Kottenberg et al., 2014),

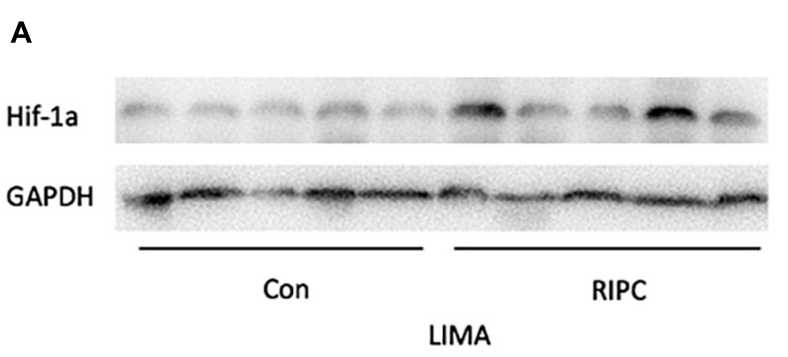

LIMA

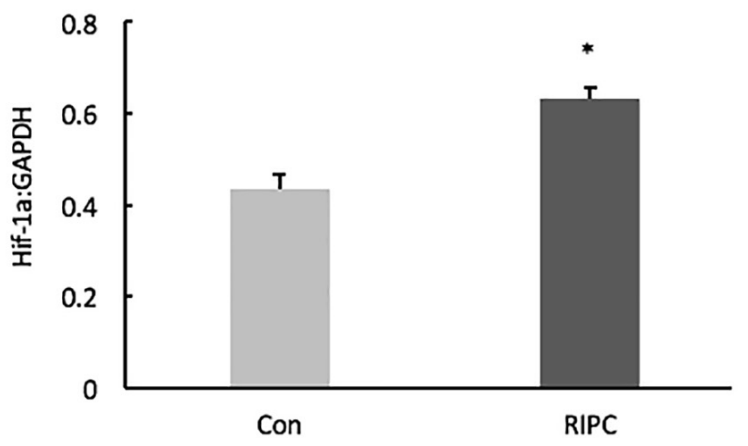

\section{B}

Hif-1a

GAPDH

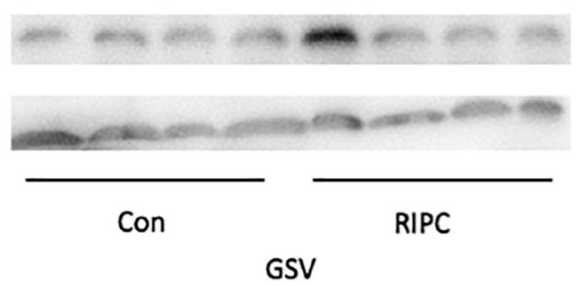

GSV

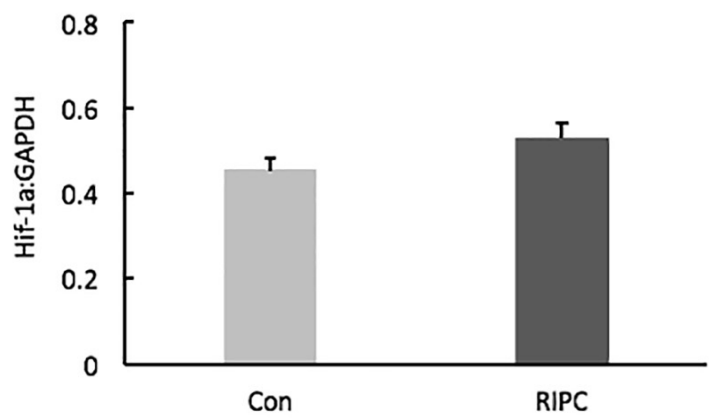

FIGURE 1 | Hif-1 $\alpha$ protein expression (Western blotting) in LIMA and GSV. (A) In LIMA samples, Hif-1 $\alpha$ protein expression in the RIPC group was higher than that in the control group. (B) In GSV samples, there was no significant difference of the Hif- $1 \alpha$ levels in vein between RIPC and control group. GSV, great saphenous vein. LIMA, left internal mammary artery. ${ }^{*} P<0.05$ vs. control group. 
which is no more cardioprotcetive than volatile anesthesia such as isoflurane (Zaugg et al., 2014; Heusch and Gersh, 2016).

In the present study, patients in control group had elevated levels of cTnT, HFABP, and IMA, indicating that the surgery indeed induces myocardial damage. RIPC treatment reduced oxidative stress, decreased production of inflammatory cytokines, downregulated protein expression of myocardial injury makers, suggesting that RIPC protects surgery-induced damage in cardiac myocytes. Of note, RIPC also reduced the supportive ventilation time, confirming the beneficial effects of RIPC treatment in the process of the surgery (Azarfarin et al., 2014).

In the present study, RIPC treatment restored OPCABGinduced oxidative stress, suggesting that RIPC systemically reduces oxidative stress after the surgery. Enhanced local inflammation induces vasoconstriction and attracts lymphocytes (Kleinbongard et al., 2011). Kharbanda et al. (2001) has shown that RIPC confers cardioprotection by reducing neutrophil activation and endothelial dysfunction in patients with valve replacement surgery. In the present study, RIPC treatment reduced inflammatory cytokines such as IL-6, IL-8, and TNF$\alpha$ levels, supporting the note that local ischemic conditioning associated with the inhibition of inflammatory responses confers cardiopretective effect (Kleinbongard et al., 2017). Antiinflammatory cytokine IL-10 may be an important factor involved in the mechanistic pathway linking the remote organ to the heart. It is reported that RIPC by 3 cycles of $5 \mathrm{~min}$ ischemia and $5 \mathrm{~min}$ reperfusion on one hind limb induces late protection against myocardial IRI by increasing the expression of IL-10 (Cai et al., 2012). In the present study, RIPC treatment reduced production of pro-inflammatory cytokines and increased anti-inflammatory cytokine, which is consistent with an acute modification of inflammatory pathways in RIPC.

The transcription factor hypoxia-inducible factor (Hif)-1 is a central oxygen-sensitive player in the protective response to hypoxia (Ong and Hausenloy, 2012). Under normoxic condition, Hif- $1 \beta$ is constitutively expressed while Hif- $1 \alpha$ is inactive. When responded to hypoxia, Hif- $1 \alpha$ is up-regulated (Prabhakar and Overholt, 2000; Prabhakar and Semenza, 2012). It is reported that RIPC increased Hif- $1 \alpha$ levels in cardiomyocytes of patients undergoing heart surgery (Albrecht et al., 2013). The mechanism of Hif- $1 \alpha$ involved in cardioprotection remains unclear (Heusch, 2012). ROS plays an important role in cardioprotection under ischaemic preconditioning, and Hif- $1 \alpha$ is a key factor in regulating cellular oxygen homeostasis (Lee et al., 2000; Semenza, 2012). During hypoxia, Hif- $1 \alpha$ regulates the enzyme composition of the mitochondrial respiratory chain to alleviate ROS formation (Fukuda et al., 2007). But now Hif-1 $\alpha$ is shown to be a prerequisite for the mitochondrial ROS formation to initiate the

\section{REFERENCES}

Ahmad, A. M., Ali, G. S., and Tariq, W. (2014). Remote ischemic preconditioning is a safe adjuvant technique to myocardial protection but adds no clinical benefit after on-pump coronary artery bypass grafting. Heart Surg. Forum 17, E220-E223. doi: 10.1532/HSF98.2014391

Albrecht, M., Zitta, K., Bein, B., Wennemuth, G., Broch, O., Renner, J., et al. (2013). Remote ischemic preconditioning regulates HIF-1alpha levels, apoptosis and protection by ischaemic preconditioning (Cai et al., 2008) In the present study, RIPC treatment upregulated Hif- $1 \alpha$ protein expressions in the LIMA, but not GSV, suggesting that artery is more sensitive to hypoxia. Further study is required to investigate the role of Hif- $1 \alpha$ for RIPC-induced cardioprotection in arteries.

\section{Study Limitations}

Overall the present study was performed with a small amount of patients and in a single center. And patients recruited were relatively aged and often companied with other systemic diseases. These factors may affect the results and conclusion in the present study. The beneficial effects of preconditioning need to be further evaluated in long-term follow-up and in large-scale clinical trials. Some references show that the intravenous anesthetic propofol possesses antioxidant properties that could obscure the effects of RIPC. Thus, in our study, sevoflurane was used to maintain depth of anesthesia. As sevoflurane has been reported to have myocardial protection, whether it interferes with the protection effect of RIPC needs further study.

\section{CONCLUSION}

Remote ischemic preconditioning protects off-pump coronary artery bypass grafting-induced cardiomyocytes damage. Better understanding of the underlying mechanism of the remote preconditioning is requested in further study.

\section{ETHICS STATEMENT}

The present study was approved by Ethnics Committee, Zhongshan Hospital, Fudan University (https://ClinicalTrials.gov \#NCT03340181).

\section{AUTHOR CONTRIBUTIONS}

HW, YH, YY, and KG designed the study. QL, LJ, and LX collected the clinical data and also managed the procedures in the Department of Anesthesiology. HW and YL wrote the manuscript, KG reviewed and revised the manuscript.

\section{FUNDING}

This study was supported by "Shanghai Medical Association Anesthesia Branch Young Physician Training Fund".

inflammation in heart tissue of cardiosurgical patients: a pilot experimental study. Basic Res. Cardiol. 108:314. doi: 10.1007/s00395-012-0314-0

Azarfarin, R., Ashouri, N., Totonchi, Z., Bakhshandeh, H., and Yaghoubi, A. (2014). Factors influencing prolonged ICU stay after open heart surgery. Res. Cardiovasc. Med. 3:e20159. doi: 10.5812/cardiovascmed. 20159

Benstoem, C., Stoppe, C., Liakopoulos, O. J., Ney, J., Hasenclever, D., Meybohm, P., et al. (2017). Remote ischaemic preconditioning for coronary artery 
bypass grafting (with or without valve surgery). Cochrane Database Syst. Rev. 5:CD011719. doi: 10.1002/14651858.CD011719.pub3

Cai, Z., Zhong, H., Bosch-Marce, M., Fox-Talbot, K., Wang, L., Wei, C., et al. (2008). Complete loss of ischaemic preconditioning-induced cardioprotection in mice with partial deficiency of HIF-1a. Cardiovasc. Res. 77, 463-470. doi: $10.1093 / \mathrm{cvr} / \mathrm{cvm} 035$

Cai, Z. P., Parajuli, N., Zheng, X., and Becker, L. (2012). Remote ischemic preconditioning confers late protection against myocardial ischemiareperfusion injury in mice by upregulating interleukin-10. Basic Res. Cardiol. 107:277. doi: 10.1007/s00395-012-0277-1

Cheung, M. M., Kharbanda, R. K., Konstantinov, I. E., Shimizu, M., Frndova, H., Li, J., et al. (2006). Randomized controlled trial of the effects of remote ischemic preconditioning on children undergoing cardiac surgery: first clinical application in humans. J. Am. Coll. Cardiol. 47, 2277-2282. doi: 10.1016/j.jacc. 2006.01.066

Chowdhury, U. K., Malik, V., Yadav, R., Seth, S., Ramakrishnan, L., Kalaivani, M., et al. (2008). Myocardial injury in coronary artery bypass grafting: on-pump versus off-pump comparison by measuring high-sensitivity C-reactive protein, cardiac troponin I, heart-type fatty acid-binding protein, creatine kinase-MB, and myoglobin release. J. Thorac. Cardiovasc. Surg. 135, 1110.e1-1119.e10. doi: 10.1016/j.jtcvs.2007.12.029

Fukuda, R., Zhang, H., Kim, J. W., Shimoda, L., Dang, C. V., and Semenza, G. L. (2007). HIF-1 regulates cytochrome oxidase subunits to optimize efficiency of respiration in hypoxic cells. Cell 129, 111-122. doi: 10.1016/j.cell.2007.01.047

Hausenloy, D. J., Candilio, L., Evans, R., Ariti, C., Jenkins, D. P., Kolvekar, S., et al. (2015). Remote ischemic preconditioning and outcomes of cardiac surgery. N. Engl. J. Med. 373, 1408-1417. doi: 10.1056/NEJMoa1413534

Hausenloy, D. J., Mwamure, P. K., Venugopal, V., Harris, J., Barnard, M., Grundy, E., et al. (2007). Effect of remote ischaemic preconditioning on myocardial injury in patients undergoing coronary artery bypass graft surgery: a randomised controlled trial. Lance. 370, 575-579.

Heusch, G. (2012). HIF-1a and paradoxical phenomena in cardioprotection. Cardiovasc. Res. 96, 214-215. doi: 10.1093/cvr/cvs145

Heusch, G. (2018). 25 years of remote ischemic conditioning: from laboratory curiosity to clinical outcome. Basic Res. Cardiol. 113:15.

Heusch, G., Botker, H. E., Przyklenk, K., Redington, A., and Yellon, D. (2015). Remote ischemic conditioning. J. Am. Coll. Cardiol. 65, 177-195. doi: 10.1016/ j.jacc.2014.10.031

Heusch, G., and Gersh, B. J. (2016). ERICCA and RIPHeart: two nails in the coffin for cardioprotection by remote ischemic conditioning? Probably not! Eur. Heart J. 37, 200-202. doi: 10.1093/eurheartj/ehv606

Kharbanda, R. K., Peters, M., Walton, B., Kattenhorn, M., Mullen, M., Klein, N., et al. (2001). Ischemic preconditioning prevents endothelial injury and systemic neutrophil activation during ischemia-reperfusion in humans in vivo. Circulation 103, 1624-1630. doi: 10.1161/01.cir.103.12.1624

Kleinbongard, P., Peters, J., Jakob, H., Heusch, G., and Thielmann, M. (2018). Persistent survival benefit from remote ischemic preconditioning in patients undergoing coronary artery bypass surgery. J. Am. Coll. Cardiol. 71, 251-262. doi: 10.1016/j.jacc.2017.10.083

Kleinbongard, P., Schulz, R., and Heusch, G. (2011). TNF-alpha in myocardial ischemia/reperfusion, remodeling and heart failure. Heart Fail. Rev. 16, 49-69. doi: 10.1007/s10741-010-9180-8

Kleinbongard, P., Skyschally, A., and Heusch, G. (2017). Cardioprotection by remote ischemic conditioning and its signal transduction. Pfluegers Arch. 469, 159-181. doi: 10.1007/s00424-016-1922-6

Kottenberg, E., Musiolik, J., Thielmann, M., Jakob, H., Peters, J., and Heusch, G. (2014). Interference of propofol with signal transducer and activator of transcription 5 activation and cardioprotection by remote ischemic preconditioning during coronary artery bypass grafting. J. Thorac. Cardiovasc. Surg. 147, 376-382. doi: 10.1016/j.jtcvs.2013.01.005

Lee, S. H., Wolf, P. L., Escudero, R., Deutsch, R., Jamieson, S. W., and Thistlethwaite, P. A. (2000). Early expression of angiogenesis factors in acute myocardial ischemia and infarction. N. Engl. J. Med. 342, 626-633. doi: 10.1056/ NEJM200003023420904

Mahesh, B., Choong, C. K., Goldsmith, K., Gerrard, C., Nashef, S. A., and Vuylsteke, A. (2012). Prolonged stay in intensive care unit is a powerful predictor of adverse outcomes after cardiac operations. Ann. Thorac. Surg. 94, 109-116. doi: 10.1016/j.athoracsur.2012.02.010

Meybohm, P., Bein, B., Brosteanu, O., Cremer, J., Gruenewald, M., Stoppe, C., et al. (2015). A multicenter trial of remote ischemic preconditioning for heart surgery. N. Engl. J. Med. 373, 1397-1407. doi: 10.1056/NEJMoa141 3579

Ong, S. G., and Hausenloy, D. J. (2012). Hypoxia-inducible factor as a therapeutic target for cardioprotection. Pharmacol. Ther. 136, 69-81. doi: 10.1016/j. pharmthera.2012.07.005

Prabhakar, N. R., and Overholt, J. L. (2000). Cellular mechanisms of oxygen sensing at the carotid body: heme proteins and ion channels. Respir. Physiol. 122, 209-221. doi: 10.1016/S0034-5687(00)00160-2

Prabhakar, N. R., and Semenza, G. L. (2012). Adaptive and maladaptive cardiorespiratory responses to continuous and intermittent hypoxia mediated by hypoxia-inducible factors 1 and 2. Physiol. Rev. 92, 967-1003. doi: 10.1152/ physrev.00030.2011 doi: 10.1152/physrev.00030.2011

Przyklenk, K., Bauer, B., Ovize, M., Kloner, R. A., and Whittaker, P. (1993). Regional ischemic "preconditioning" protects remote virgin myocardium from subsequent sustained coronary occlusion. Circulation 87, 893-899. doi: 10. $1159 / 000108686$

Sakpal, T. V. (2010). Sample size estimation in clinical trial. Perspect. Clin. Res. 1, 67-69.

Sellke, F. W., Chu, L. M., and Cohn, W. E. (2010). Current state of surgical myocardial revascularization. Circ. J. 74, 1031-1037. doi: 10.1253/circj.cj-100321

Semenza, G. L. (2012). Hypoxia-inducible factors in physiology and medicine. Cell 148, 399-408. doi: 10.1016/j.cell.2012.01.021

Thielmann, M., Kottenberg, E., Kleinbongard, P., Wendt, D., Gedik, N., Pasa, S., et al. (2013). Cardioprotective and prognostic effects of remote ischaemic preconditioning in patients undergoing coronary artery bypass surgery: a single-centre randomised, double-blind, controlled trial. Lancet 382, 597-604. doi: 10.1016/S0140-6736(13)61450-6

Wu, Q., Wang, T., Chen, S., Zhou, Q., Li, H., Hu, N., et al. (2018). Cardiac protective effects of remote ischaemic preconditioning in children undergoing tetralogy of fallot repair surgery: a randomized controlled trial. Eur. Heart J. 39, 1028-1037. doi: 10.1093/eurheartj/ehx030

Xie, J., Zhang, X., Xu, J., Zhang, Z., Klingensmith, N. J., Liu, S., et al. (2018). Effect of remote ischemic preconditioning on outcomes in adult cardiac surgery: a systematic review and meta-analysis of randomized controlled studies. Anesth. Analg. 127, 30-38. doi: 10.1213/ANE.00000000000 02674

Xue, M., and Xu, H. (2017). Summary of the forum on integration of traditional Chinese and Western medicine. Chin. J. Integr. Tradit. West. Med. 10:1270.

Zaugg, M., Lucchinetti, E., Behmanesh, S., and Clanachan, A. S. (2014). Anesthetic cardioprotection in clinical practice from proof-of-concept to clinical applications. Curr. Pharm. Des. 20, 5706-5726. doi: 10.2174/ 1381612820666140204120829

Conflict of Interest Statement: The authors declare that the research was conducted in the absence of any commercial or financial relationships that could be construed as a potential conflict of interest.

Copyright $\odot 2019$ Wang, Lyu, Liao, Jin, Xu, Hu, Yu and Guo. This is an open-access article distributed under the terms of the Creative Commons Attribution License (CC BY). The use, distribution or reproduction in other forums is permitted, provided the original author(s) and the copyright owner(s) are credited and that the original publication in this journal is cited, in accordance with accepted academic practice. No use, distribution or reproduction is permitted which does not comply with these terms. 